\title{
Perfil dos egressos do curso de Nutrição da Universidade Federal de Lavras
}

\author{
Profile of Nutrition students who graduated from \\ Universidade Federal de Lavras
}

\author{
Juliana Silva Franco', Sandra Bragança Coelho² \\ 'Universidade Federal de Lavras - Departamento de Nutrição da Universidade Federal de \\ Lavras (DNU-UFLA) \\ 2Universidade Federal de Lavras - Docente do Departamento de Nutrição da Universidade \\ Federal de Lavras (DNU-UFLA)
}

E-mail para contato: Juliana Silva Franco - julianasfranco@live.com

\begin{abstract}
Resumo
O presente estudo tem como objetivo traçar o perfil dos egressos do curso de Nutrição da Universidade Federal de Lavras (UFLA), desde a sua criação até 2018/1. Os nutricionistas formados pela UFLA foram convidados a participar do estudo por e-mail obtido através do coordenador do curso e os que aceitaram, após assinar o Termo de Consentimento Livre e Esclarecido, receberam o acesso ao questionário da pesquisa para ser respondido online, neste questionário haviam questões afim de caracterizar a amostra e questões referentes à inclusão no mercado de trabalho. Dos 176 egressos do curso de Nutrição que ingressaram entre o segundo semestre de 2009 e o segundo semestre de 2014, 73,29\% responderam ao questionário. Destes, 68,22\% escolheram a Nutrição por ter afinidade pela área da saúde, demonstrando maior preferência por atuação na área clínica ao ingressar $(37,21 \%)$ e a maioria está atuando apenas nesta área (28,7\%). Ao se formar, a maioria possuía entre 23 e 25 anos (53,49\%), 62,79\% dos egressos se consideram satisfeitos ou muito satisfeitos com o trabalho atual, a faixa salarial está concentrada entre 2 e 3 salários mínimos, 45,74\% afirmaram estar fazendo especialização em nutrição e 17,05\% já fizeram. Sugere-se a continuação deste estudo, a fim de que o curso possa refletir as necessidades do mercado de trabalho, que está em constante transformação.
\end{abstract}

Palavras-chave: Graduados. Nutricionista. Desempenho profissional. Mercado de trabalho.

\begin{abstract}
The purpose of this study is to outline the profile of the graduates of UFLA's Nutrition course, from its creation to 2018/7. The nutritionists whom graduated from UFLA were invited to participate in the study by e-mail obtained from the course coordinator and those who accepted, after signing the Free and Informed Consent Term received the access to the questionnaire of the research to be answered online, in this questionnaire there were questions in order to characterize the sample and questions regarding inclusion in the labor market. Of the 176 graduates of the Nutrition course who enrolled between the second semester of 2009 and the second semester of 2014, 73.29\% answered the questionnaire. Of these, $68,22 \%$ chose Nutrition because it has affinity with the health area, demonstrating a greater preference for job performance in clinical
\end{abstract}


nutrition upon admission to university $(37,21 \%)$ and most of them are working only in this area (28,7\%). When they graduated, most of them were aged between 23 and 25 years old (53,49\%), 62,79\% of the graduates consider themselves satisfied or very satisfied with their current job, the salary range is concentrated between 2 and 3 minimum wages, $45,74 \%$ asserted to be doing specialization in nutrition and $17,05 \%$ had already done it. The development of this study is suggested for the purpose of reflecting the needs of this labor market that is constantly changing.

Keywords: Graduate. Nutritionist. Job performance. Labor market.

\section{INTRODUÇÃO}

Os primeiros cursos voltados para a área de alimentação e nutrição do Brasil foram implantados em 1939 no Estado de São Paulo e na então capital do país, Rio de Janeiro, durante o governo de Getúlio Vargas ${ }^{1}$.

O nutricionista, quando surgiu no Brasil, era conhecido como dietista; sua área de atuação era em uma equipe técnica individualista, tendo como atribuição cuidar dos pacientes através da alimentação².

A partir da década de 40 do século passado, o mercado de trabalho do nutricionista no Brasil foi influenciado pela evolução do capitalismo vinculado à política populista, gerando modificações na formação acadêmica e ajustando os currículos às oportunidades oferecidas pela realidade brasileira da época².

Os ajustes continuaram acontecendo, haja vista que o perfil epidemiológico da população se modificou ao longo das décadas: o quadro de desnutrição diminuiu junto com o número de mortes por doenças infecciosas e parasitárias, enquanto o sobrepeso e obesidade passaram a ser mais preocupantes. Assim, o perfil profissional deve adequar-se às exigências do mercado de trabalho e contemplar o sistema de saúde vigente no país, o trabalho em equipe e a atenção integral à saúde’3. O reconhecimento da formação superior do profissional nutricionista ocorreu em 1962, com a publicação do Parecer n ${ }^{0} 265$ do então Conselho Federal de Educação. A partir de 1964, foi estabelecido o primeiro currículo mínimo de matérias e fixada a duração de três anos para todos os cursos a nível nacional, mas a regulamentação da profissão só aconteceu em 1967, pela Lei no 5.276/67, momento no qual o Brasil contava com 6 cursos. Nas décadas seguintes, o número de cursos começou a se expandir por todas as regiões do país, surgindo 38 novos cursos até 1996, quando foi promulgada a Lei no 9.394, de 20/12/1996 - Lei de Diretrizes e Bases da Educação Nacional ${ }^{4}$. 
Quase 80 anos depois da criação dos primeiros cursos de Nutrição no Brasil, já são ofertados 628 cursos presenciais ativos de Bacharelado em Nutrição. Destes, 66 estão localizados no Estado de Minas Gerais ${ }^{5}$. Os egressos destes cursos podem exercer a profissão de nutricionista apenas a partir do momento em que estão registrados no Conselho Regional de Nutricionistas (CRN) de seu respectivo estado ou região ${ }^{6}$.

A criação do Bacharelado em Nutrição na Universidade Federal de Lavras (UFLA) foi proposta pelo Departamento de Ciência dos Alimentos da mesma, baseada na crescente necessidade de ter profissionais competentes habilitados no setor de alimentação e nutrição humana na região, capazes de orientar a alimentação da população em suas diferentes fases da vida, na saúde e nas patologias que venham a apresentar7.

Em 10 de agosto de 2009, o curso de nutrição entrou em vigor, contando com 2 professoras formadas em nutrição. No primeiro semestre do curso, foram ofertadas 25 vagas e, a partir de 2011, esse número foi duplicado. Hoje a Universidade Federal de Lavras oferece 50 vagas por semestre no Bacharelado em Nutrição. O Departamento de Nutrição (DNU) conta hoje com 19 professores doutores nutricionistas, com três técnicas de nível superior também nutricionistas, e teve seu primeiro chefe eleito pelos seus pares ${ }^{7,8}$.

O presente estudo teve como objetivo conhecer o perfil do egresso do Curso de Nutrição da UFLA, a fim de utilizar estas informações para nortear o Projeto Pedagógico do Curso e, com isso, mensurar a qualidade do ensino pautada no entendimento da situação mercadológica e nos desafios enfrentados pelos profissionais formados por esta Instituição.

\section{MÉTODO}

Este é um estudo transversal e descritivo, onde foram utilizadas informações quantitativas e qualitativas obtidas com o auxílio de um questionário online, a fim de traçar o perfil dos egressos do curso de Nutrição, desde a sua criação até o primeiro semestre de 2018.

Inicialmente com o auxílio da coordenação do curso, foram obtidos os nomes, contato telefônico e e-mail de todos os egressos do curso de Nutrição do segundo semestre de 2013 (primeira turma de concluintes) até o primeiro semestre de 2018. Uma vez com estas informações em mãos, todos os egressos foram contatados por 
e-mail, meio utilizado para explicar os objetivos e os procedimentos necessários para a participação no estudo. Os egressos, que não responderam da primeira vez, foram contatados novamente por e-mail e, em seguida, por contato telefônico. Alguns egressos foram contatados por redes sociais (Facebook e Instagram) informadas por seus colegas de turma ou por busca pelo nome e sobrenome. Os egressos foram convidados a participar do estudo; e ao aceitarem, assinaram o Termo de Consentimento Livre e Esclarecido (TCLE) aprovado pelo Comitê de Ética em Pesquisa com Seres Humanos da UFLA sob nº CAAE 89813718.6.0000.5148. Em seguida, receberam o acesso ao questionário da pesquisa para ser respondido online. Esse questionário apresentava inicialmente questões a fim de caracterizar a amostra (sexo, idade, período de ingresso e de conclusão do curso) e as questões referentes à sua inclusão no mercado de trabalho (principais dificuldades encontradas na área de atuação, faixa salarial, se está fazendo ou já concluiu alguma especialização). Uma vez com os questionários respondidos, foi realizada a análise descritiva dos dados obtidos por meio de frequência percentual e média.

\section{RESULTADOS}

Dos 176 egressos do curso de Nutrição da UFLA que ingressaram entre o segundo semestre de 2009 e o segundo semestre de 2014, cinco não foram localizados. Destes, 129 responderam ao questionário, correspondendo a $73,29 \%$ do total dos concluintes no curso de Nutrição da UFLA entre 2013/2 e 2018/1. Dos respondentes, $92,25 \%$ eram do sexo feminino e $7,75 \%$ do sexo masculino.

No que diz respeito à vida acadêmica anterior à UFLA, a maior parte dos egressos do curso de Nutrição $(48,06 \%)$ estudou durante o ensino fundamental e médio em escolas públicas, somente $20,93 \%$ vieram exclusivamente de escolas particulares, e os $31,01 \%$ restantes estudaram em ambas.

Os respondentes estão distribuídos por 11 períodos de ingresso, variando de 2009/2 até 2014/2. Os semestres nos quais houve maior participação foram 2009/2 (100\%), $2014 / 2(100 \%)$ e $2010 / 1(85,71 \%)$, e o de menor participação foi 2013/1 onde apenas $60 \%$ participou da pesquisa.

A maioria dos discentes do curso de Nutrição da UFLA $(64,34 \%)$ ingressou na universidade com idade entre 17 e 19 anos. Cerca de um quarto ingressou com idade entre 20 e 22 anos (24,03\%); e a média de idade foi 19,37 anos. Ao se formar, a maioria possuía entre 23 e 25 anos (53,49\%). Em menor número vêm os concluintes 
que possuíam entre 20 e 22 anos (19,38\%) e 26 a 28 anos (17,83\%). A idade máxima no momento da conclusão do curso neste presente estudo foi de 40 anos, a mínima foi de 21 anos e a idade média foi de 24,65 anos.

Quanto aos motivos da escolha do curso de Nutrição, os entrevistados podiam escolher mais de uma opção de resposta e a maioria afirmou ter afinidade pela área de saúde $(68,22 \%)$, reconhecendo a nutrição como um curso de cuidado ao próximo, ao estudar a relação do homem com o alimento para preservar sua saúde. Porém, apenas $45,31 \%$ dos egressos afirmaram ter afinidade específica pelo curso de Nutrição. Essa baixa demanda específica pode ser, também, a razão de desistência/abandono do curso pelos estudantes durante a graduação. Em menor quantidade, foram escolhidas as opções de aprovação mesmo sem ser a primeira opção de curso preferido na época (segunda escolha com 17,83\%), obtenção de um diploma de nível superior (12,4\%), entre outros correspondendo a 6,98\% (influência de terceiros, horário das aulas do curso e facilidade para ingressar).

Quando indagados sobre o motivo de escolha da UFLA, onde podiam escolher quantas opções fossem convenientes, o ensino de qualidade e gratuito foram as respostas mais escolhidas com $64,34 \%$ e $44,19 \%$ respectivamente, reflexo da boa reputação construída ao longo dos anos por esta universidade. Proximidade com a cidade natal $(39,53 \%)$, aprovação sem ser a primeira opção preferida na época (segunda escolha) $(19,38 \%)$, qualidade de vida na cidade de Lavras, uma cidade localizada no interior de Minas Gerais, relativamente segura e com custo de vida inferior $(16,28 \%)$ - quando comparada à metrópoles, considerada um polo educacional e de trabalho para a região, boa aceitação pelo mercado de trabalho $(10,85 \%)$ e outros 3,88\% (influência de terceiros, alojamento estudantil e beleza do campus) foram as opções menos selecionadas.

Foi perguntado se os formandos já sabiam em qual área da nutrição gostariam de seguir carreira ao ingressarem na Universidade. Eles puderam escolher mais de uma resposta e observa-se que a maior parte da amostra quando ingressou no curso ainda não sabia qual área queria seguir (41,08\%) (Figura 1). Dos que já sabiam qual área seguir, 37,5\% tinha interesse em atuar na área de nutrição clínica (Figura 1). Este percentual de atuação nos dias atuais é de $28,3 \%$, e é a área na qual a maioria dos egressos está atuando no momento, sem contabilizar os egressos que estão atuando nessa área e em outra(s), como aponta a Figura 2. 
O interesse por saúde coletiva inicialmente era pequeno $(6,2 \%)$, porém, após a realização das disciplinas específicas desta área, a atuação profissional ficou em torno de 9,26\%. O mesmo fenômeno ocorreu com a área de Alimentação Coletiva, onde inicialmente $4,65 \%$ gostariam de atuar na área, mas após a formatura $8,33 \%$ dos egressos atuando em Unidades de Alimentação e Nutrição (Figura 1 e 2).

As áreas com maior tempo de atuação pelos egressos são Saúde Coletiva e Alimentação Coletiva. Mesmo assim, estas apresentam no máximo 2 anos de atuação. Isso se pode dever à troca de áreas de atuação e também ao fato de o curso de Nutrição da UFLA ainda ser um curso jovem, tendo sua primeira turma de egressos em dezembro de 2013.

Figura 1 - Distribuição percentual da área de interesse dos formandos ao ingressar no curso (n=129) 141 respostas

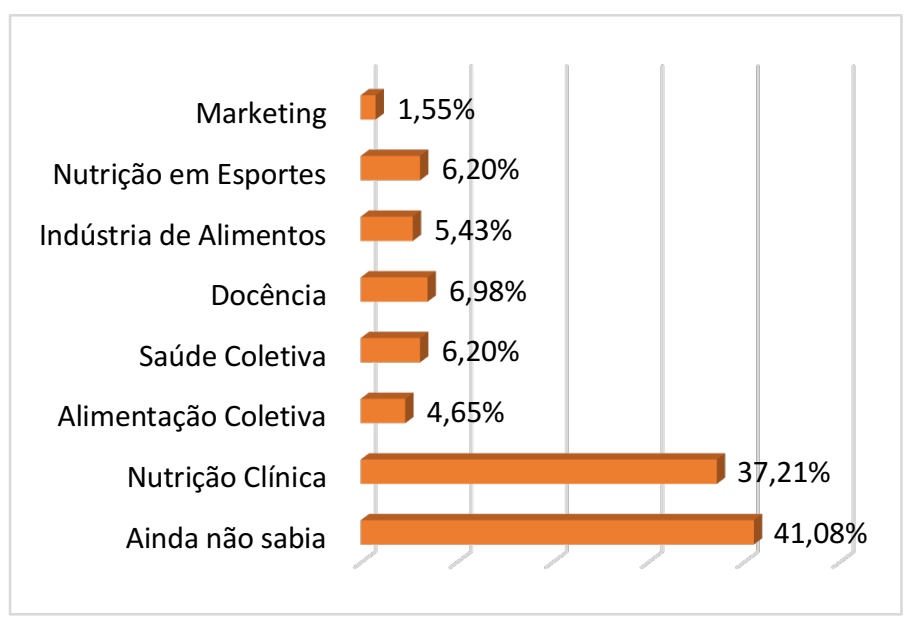

Figura 2 - Distribuição percentual da área de atuação dos formandos nos dias atuais (n=108)

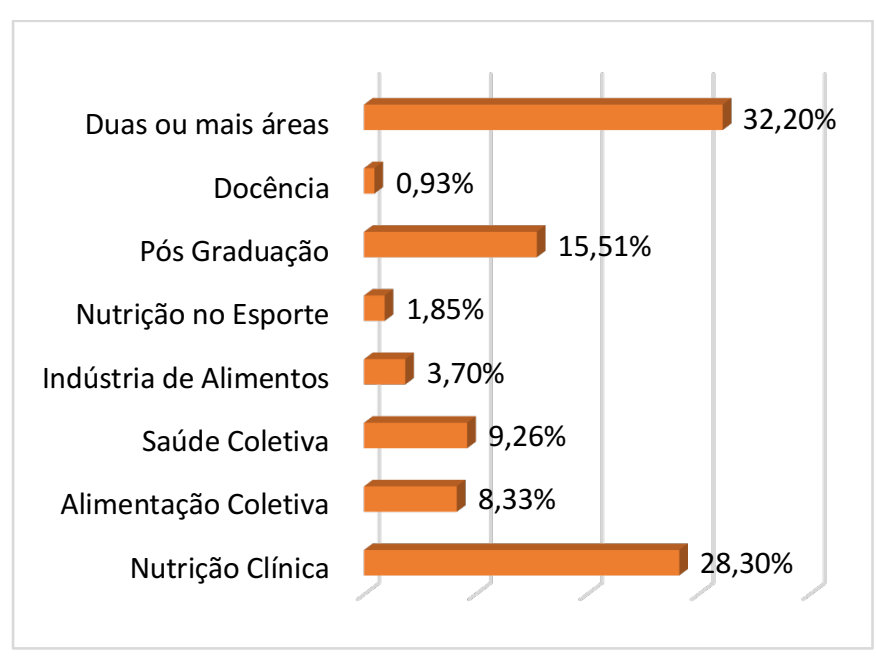

Os egressos também foram questionados sobre o grau de satisfação com a suas ocupações atuais dentro da área de Nutrição e 62,79\% dos egressos se consideram 
satisfeitos ou muito satisfeitos com o trabalho atual, 17,82\% estão pouco ou nada satisfeitos e 19,39\% não trabalha.

Quase metade dos egressos (48,84\%) considera a falta de valorização profissional uma dificuldade na área de atuação escolhida. As demais dificuldades relatadas são em relação ao mercado de trabalho competitivo, carga horária elevada, falta de prática e outros (falta de recursos, dificuldade em captação de pacientes e falta de comprometimento dos mesmos, instabilidade e não gostar da área de atuação). Constata-se ainda que $19,37 \%$ relataram que não exerciam nenhuma atividade no momento, e 1,55\% (atuantes em nutrição clínica e indústria de alimentos) relataram não possuir dificuldade alguma.

A área que apresentou profissionais com os melhores salários (mais que 4 salários mínimos) foi nutrição clínica e, quando estes profissionais exerciam atividades em 2 ou mais áreas, destes, 26,5\% estavam atuando em nutrição clínica e saúde coletiva, e 17,7\%, em nutrição clínica e nutrição esportiva.

A faixa salarial que apresentou maior percentual entre os egressos do curso de Nutrição da UFLA, e a média salarial em quase todas as áreas de atuação foi a de 2 a 3 salários mínimos (Figura 3).

A área onde foi observado um maior percentual dos menores salários (até 1 salário mínimo) foi a de Nutrição no Esporte (50\%), seguida pelas da Nutrição Clínica (25\%) e da Indústria de Alimentos (25\%) (Figura 3).

Do total de respondentes, $6,2 \%(n=8)$ estavam fazendo pós graduação sem remuneração e, dos demais que apresentavam renda, 56\% destes profissionais relataram renda variando de 2 a 3 salários mínimos (Figura 3 ).

No tocante à renda relacionada ao tempo de formação, os egressos que recebem mais de 4 salários mínimos por mês foram os das primeiras turmas, que se graduaram até 2015/1, com um pouco mais de 3 anos de formados, e dos que ganham até 1 salário mínimo, onde $42 \%$ colou grau em $2018 / 1$, ou seja, quando responderam à pesquisa tinham se formado há apenas 6 meses. Pode-se concluir com isso que no caso dos egressos do curso de Nutrição da UFLA, quanto maior o tempo de formação, maior foi o salário destes profissionais. 
Figura 3 - Distribuição percentual da renda dos egressos do curso de Nutrição em suas respectivas áreas de atuação. $(n=108)$

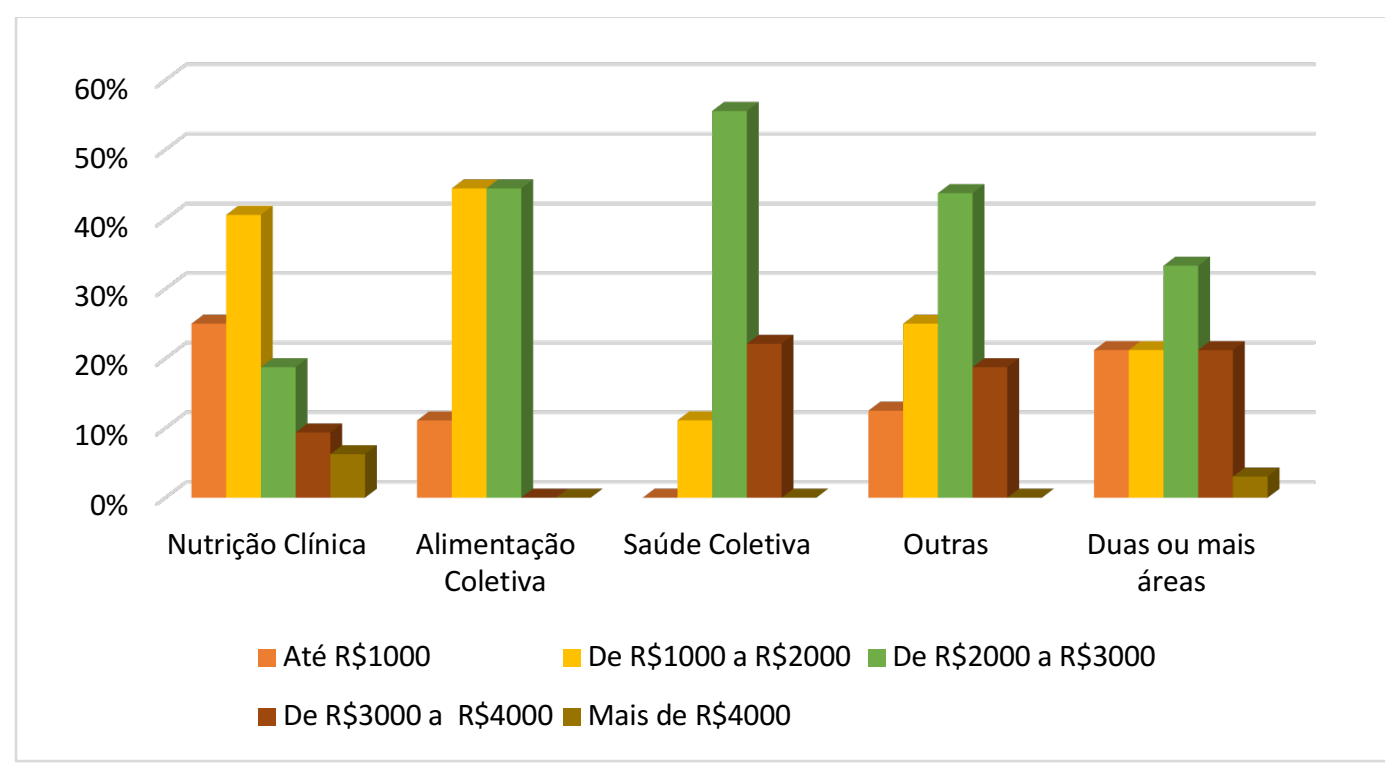

Os egressos também foram questionados se estavam cursando alguma especialização, e 45,74\% afirmaram estar cursando algum curso de especialização, e 17,05\% disseram já ter concluído alguma especialização. Foi oferecida aos respondentes a opção de marcar mais de uma área, caso estivessem cursando ou já tivessem cursado mais de uma especialização (Figura 4). O grande número de respondentes que ainda não concluíram nenhuma especialização pode estar associado ao curto tempo de atuação após a colação de grau.

Figura 4 - Distribuição percentual da área onde os egressos do curso de Nutrição estão fazendo e/ou já concluíram especialização. (n=59/22)

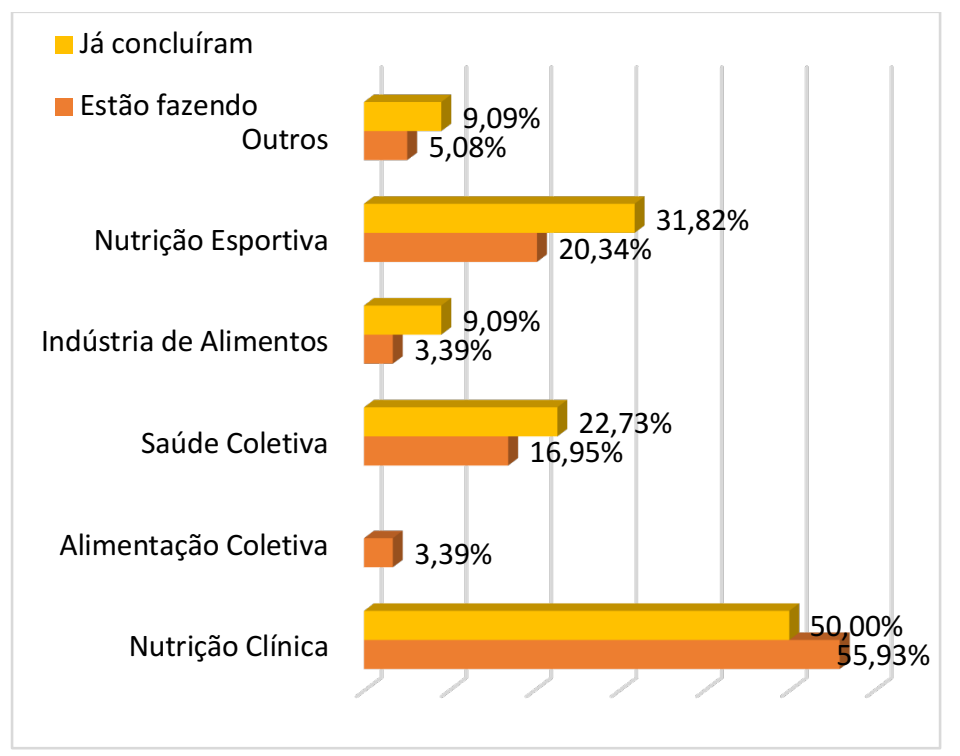


A área de maior interesse para especializações nos egressos do curso de Nutrição da UFLA foi a área de nutrição clínica, como esperado, haja vista que é onde o maior número de egressos estavam trabalhando, seguida da área de nutrição esportiva, uma área que vem ganhando espaço e importância, e de saúde coletiva, como demonstrado na Figura 4.

\section{DISCUSSÃO}

Do total de concluintes do curso de Nutrição da UFLA entre 2013/2 e 2018/1, este estudo obteve $73,29 \%$ de respondentes, uma alta adesão se comparada a estudos que obtiveram menos de $45 \%$ de respostas como os de Feix \& Poll ${ }^{9}$, Rodrigues et $\mathrm{al}^{10} \mathrm{e}$ Gambardella et $\mathrm{al}^{11}$.

O maior número de mulheres formadas no curso de Nutrição da UFLA (92,25\%) mantém um padrão seguido ao longo dos anos entre os cursos de Nutrição do Brasil. Este padrão pode ser observado através de pesquisas como a de Soar \& Silva ${ }^{12}$, que mostrou que $97,5 \%$ dos egressos da Universidade do Vale do Paraíba eram mulheres, e a de Vasconcelos \& Calado ${ }^{1}$, que verificou que $96,5 \%$ de nutricionistas que atuavam no Brasil em 2005 eram do sexo feminino.

A maioria dos egressos possuía entre 23 e 25 anos (53,49\%) ao se graduarem. Dados semelhantes aos observados por Sabba et al. ${ }^{13}$ no perfil dos egressos de Nutrição da Universidade Paulista (UNIP) de um campus em São Paulo, onde 51,5\% tinham entre 20 e 25 anos no momento da conclusão do curso.

A idade média ao se formarem foi de 24,65 anos. Dados congruentes com

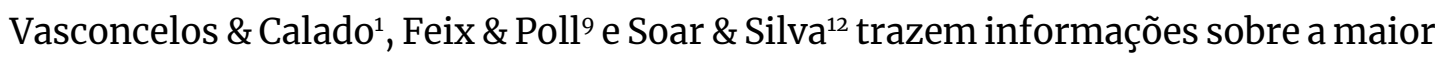
atuação de nutricionistas no mercado de trabalho brasileiro que podem ser classificados como adultos jovens possuindo entre 20 e 30 anos.

O fato de $41,08 \%$ dos egressos não saber qual área queria seguir ao ingressar no curso, reflete a importância da disciplina de Introdução à Nutrição, cujo objetivo é esclarecer aos ingressantes os aspectos importantes do curso de Nutrição da UFLA e as áreas de atuação, entre outras informações pertinentes, logo no primeiro semestre.

A oferta de disciplinas eletivas relacionadas à nutrição clínica, para um melhor embasamento prático-teórico é de suma importância tendo em vista que é a área que mais interessa aos ingressantes no curso e é a área com mais nutricionistas atuando. Caso diferente da área de docência, na qual demonstraram mais interesse ao 
ingressar e, atualmente, têm uma pequena atuação, o que pode estar relacionado ao fato de os egressos não terem se formado há tanto tempo, por ser um curso relativamente novo, e para concluir um mestrado e um doutorado são necessários alguns anos.

Em relação ao grau de satisfação com a suas ocupações atuais dentro da área de Nutrição $17,05 \%$ estão pouco ou nada satisfeitos e dados semelhantes aos de Gambardella et al ${ }^{10}$ onde $21,3 \%$ dos nutricionistas oriundos da Curso de Nutrição da Faculdade de Saúde Pública (Universidade de São Paulo) manifestaram-se insatisfeitos no exercício da profissão.

Entre os 19,38\% que não trabalham, mais da metade (55\%) é composta por egressos que se formaram em 2017/2 e 2018/1, últimos períodos analisados neste estudo. Certa dificuldade é esperada para ingresso e sucesso no mercado de trabalho logo após a graduação. Alguns obstáculos vivenciados são a insegurança por falta de experiência e a grande quantidade de cursos de Nutrição espalhados pelo Brasil, que gera um grande número de profissionais atuando nos dias de hoje, aumentando a concorrência.

A segunda maior dificuldade na área de atuação informada pelos egressos é a baixa remuneração, mas, SABBA et $\mathrm{al}^{13}$ relata que grande parte dos nutricionistas egressos da Universidade Paulista (59,1\%) estava satisfeita financeiramente com a carreira.

A média salarial em quase todas as áreas de atuação foi a de 2 a 3 salários mínimos. Esse dado está coerente com o estudo de Soar \& Silva ${ }^{12}$ sobre a Universidade do Vale do Paraíba, que encontrou um maior número de nutricionistas atuando com faixa salarial entre 2 e 3,2 salários mínimos. E os de SABBA et $\mathrm{al}^{13}$ onde a faixa salarial recebida por $81,8 \%$ dos profissionais foi inferior a 5 salários mínimos. Já o estudo de Gambardella et $\mathrm{al}^{10}$ observou resultado diverso, onde a maioria dos nutricionistas egressos da Universidade de São Paulo ganhava entre 10 e 15 salários mínimos. No Rio Grande do Sul, Dalla-Lana ${ }^{14}$ relatou o ganho de 4 a 5 salários mínimos pelos egressos da Universidade Federal do Rio Grande do Sul (UFRS).

Uma das áreas com menor número de pessoas atuando foi a Nutrição em Esportes. Isto se deve ao fato de ser uma área relativamente nova, onde o nutricionista tem mostrado sua importância e vem conseguido espaço.

$\mathrm{Na}$ área específica de Alimentação Coletiva, a maioria dos egressos do curso de Nutrição (89\%) apresentaram uma renda entre 1 e 3 salários mínimos, dado que foi 
diverso ao encontrado por Rodrigues et $\mathrm{al}^{11}$ que verificou uma remuneração de 5,34 salários mínimos para esta área. Quanto ao rendimento mensal dos nutricionistas atuantes no Programa Nacional de Alimentação do Escolar (PNAE), pertencente à área de saúde coletiva, Mello et $\mathrm{l}^{15}$ observou a predominância salarial entre 2 e 5 salários mínimos.

Na área de Nutrição Clínica observou-se que aproximadamente $41 \%$ da amostra afirmou ter remuneração de 1 a 2 salários mínimos, salários que foram inferiores aos relatados por Rodrigues et $\mathrm{al}^{11}$, que encontraram uma média de 4,9 salários para os profissionais atuando nesta área.

Já na área de Saúde Coletiva, 56\% da amostra estudada relatou ter renda de 2 a 3 salários mínimos. Esse achado foi semelhante ao encontrado no estudo de Rodrigues et $\mathrm{al}^{11}$, onde os profissionais atuando nesta área apresentaram renda de 3,6 salários mínimos.

O percentual de 45,74\% que afirmou estar cursando algum curso de especialização, se assemelha ao estudo de Gambardella et $a^{10}$ que demonstrou que $37,1 \%$ dos egressos do curso de Nutrição da USP estavam se especializando. Em relação aos que já haviam concluído alguma pós graduação, os 17,05\% da UFLA divergem dos 77\% da UFRGS ${ }^{10}$. Isso pode ser explicado pelo pouco tempo de existência do curso na UFLA e consequentemente pouco tempo de formação dos egressos.

Os egressos podiam responder ao final da pesquisa quais sugestões de melhorias acreditavam ser pertinentes na matriz curricular e quase metade da amostra $(48,06 \%)$ sentiu falta de aulas práticas durante a graduação. A maior oferta de estágios também foi citada $(16,28 \%)$, tanto em relação ao aumento de horas para cada estágio, como também referente à possibilidade de estagiar antes do último semestre. Alguns egressos (15,5\%) acreditam que poderiam ser incluídos na matriz curricular mais conceitos de administração (para organizar melhor um consultório) e marketing para divulgação do trabalho e captação de novos pacientes/clientes. Outros $6,2 \%$ sugeriram mais contato com o mercado de trabalho, referente às visitas técnicas e visitas de mais profissionais no espaço acadêmico, para falarem sobre sua atuação. Um número menor sugeriu um enfoque maior em nutrição comportamental, que está muito em voga atualmente, e em alimentação coletiva. Outros ainda mencionaram que o curso deveria trazer mais incentivo à pesquisa e às atividades de extensão, incluir disciplina eletiva de plantas medicinais, tornar a eletiva de alimentos funcionais obrigatória, criar disciplina eletiva com 
embasamento para atendimento domiciliar e para consultoria e assessoria em Nutrição.

Atualmente o curso de Nutrição da UFLA possui 9 períodos letivos, sendo 8 de disciplinas e 1 de estágio. Das 2635 horas aula de disciplinas obrigatórias do curso de Nutrição da UFLA, apenas 595 horas (22,58\%) contemplam disciplinas estritamente teóricas, ou seja, 77,41\% das disciplinas obrigatórias do curso de Nutrição da UFLA é composto por disciplinas que apresentam conteúdo prático ${ }^{16}$.

Para começarem a estagiar, os estudantes devem ter sido aprovados em todas as disciplinas ofertadas anteriormente e no último semestre devem cumprir no mínimo 732 horas de estágio divididas igualmente entre 3 áreas obrigatórias: Nutrição Clínica, Nutrição Social e Unidade de Alimentação ${ }^{16}$.

No ano de 2019 estavam em andamento cerca de 30 projetos de extensão, atendendo 23 bolsistas e 73 alunos que estavam trabalhando em projetos voluntariamente ${ }^{16}$.

Recentemente foram criadas novas disciplinas eletivas para atender as demandas dos alunos, por isso hoje o curso de Nutrição da UFLA conta com as disciplinas de Bases teóricas do comportamento alimentar, Atendimento nutricional e Rotulagem e legislação de alimentos no seu rol de disciplinas eletivas.

\section{CONCLUSÃO}

Pode-se concluir que os egressos do curso de Nutrição da UFLA são, em sua maioria, mulheres que se formaram com a faixa etária de 23 a 25 anos advindas de escolas públicas.

A maioria escolheu a Nutrição por ter afinidade pela área da saúde, porém ao ingressar a maior parte ainda não sabia em qual área da nutrição seguiria. Os que já sabiam em qual área gostariam de atuar demonstraram maior interesse por atuar em nutrição clínica ao ingressar, sendo atualmente a área na qual o maior número de egressos está atuando. Esta também é a área onde mais egressos buscaram se especializar, além da área de nutrição esportiva.

A maioria dos egressos do curso de Nutrição da UFLA se considerou satisfeita ou muito satisfeita com o trabalho atual, possuindo uma faixa salarial concentrada entre 2 e 3 salários mínimos.

Mais aulas práticas e estágios foram citados pelos egressos como sugestões que poderiam ser feitas para melhorar a qualidade do curso. 
Sugere-se a continuação deste estudo, abordando os egressos do curso de Nutrição, a fim de que o curso possa refletir as necessidades do mercado de trabalho que está em constante transformação.

\section{REFERÊNCIAS}

1. Vasconcelos FAG, Calado CLA. Profissão nutricionista: 70 anos de história no Brasil. Revista de Nutrição, Campinas, p. 605-617, 2011.

2. Costa NMSC. Revisitando os estudos e eventos sobre a formação do nutricionista no Brasil1. Revista de Nutrição, Campinas, p. 05-19, 1999.

3. Ceccim RB, Feurwerker LCM. Mudança na graduação das profissões de saúde sob o eixo da integralidade. Cad. Saúde Pública, Rio de Janeiro, v.20, n. 5, p. 1400-10, set./out., 2004.

4. Calado CLA. A expansão dos Cursos de Nutrição no Brasil e a nova Lei de Diretrizes e Bases - LDB, [200-?]. Disponível em

<http://www.cfn.org.br/novosite/pdf/expansao.pdf>. Acesso em 22 de abril de 2018.

5. E-MEC. Instituições de Educação Superior e Cursos Cadastrados. Disponível em: <http://emec.mec.gov.br/> Acesso em 25 de abril de 2018

6. Conselho Federal de Nutricionistas. Resolução CFN No 380 , de 28 de Dezembro de 2005. Disponível em: <http://www.cfn.org.br/wpcontent/uploads/resolucoes/Res_380_2005.htm>. Acesso em: 26 de abril de 2018.

7. Departamento de nutrição da UFLA. Curso de Nutrição - Projeto Pedagógico do Curso. Lavras, 2013).

8. Departamento de Nutrição da UFLA. Histórico. Disponível em: <http://www.dnu.ufla.br/institucional/historico>, [201-?] Lavras. MG. Acesso em 10 de abril de 2019.

9. Feix M, Poll FA. Perfil profissional de nutricionistas egressos da Universidade de Santa Cruz do Sul. Revista do Departamento de Educação Física e Saúde e do Mestrado em Promoção da Saúde da Universidade de Santa Cruz do Sul / Unisc. Ano 16 - Volume 16 - Número 4 - Outubro/Dezembro, 2015.

10. Gambardella AMD, Ferreira CF, Frutuoso MFP. Situação profissional de egressos de um curso de nutrição. Rev. Nutr., Campinas, 13(1): 37-40, jan./abr., Florianópolis, Santa Catarina (SC), 2000.

11. Rodrigues KM, Peres F, Waissmann W. Condições de trabalho e perfil profissional dos nutricionistas egressos da Universidade Federal de Ouro Preto, Minas Gerais, entre 1994 e 2001. Ciência \& Saúde Coletiva, v.12, n.4, p.1021-1031, 2007.

12. Soar C, Silva CAM. Perfil e carreira de egressos de Nutrição da Região do Vale do Paraíba-SP. São Paulo, SP. p. 1013-1029, 2017.

13. SABBA LJ, Okida Y, Oliveira CRA, Coutinho RMC, Coelho HDS. Perfil de egressos do curso de nutrição da Universidade Paulista de um campus em São Paulo. J Health Sci Inst. 2014;32(4):424-7, 2014. 
14. Dalla-Lana M. Estudo sobre a situação profissional dos egressos do curso de nutrição da Universidade Federal do Rio Grande do Sul. Porto Alegre (RS), 2010.

15. Mello AL Vidal Júnior PO, Sampaio LR, Santos LAS, Freitas MCS, Fontes GAV. Perfil do nutricionista do programa nacional de alimentação escolar na região Nordeste do Brasil, Revista de Nutrição, Campinas, 25(1):119-132, jan./fev., 2012

16. Departamento de Nutrição da UFLA. Curso de Nutrição - Projeto Pedagógico do Curso. Lavras. Em fase de elaboração..

Submissão: $25 / 03 / 2020$

Aprovação: 05/01/2021 